NASA/TM-2000-209779

A. 21

Design of a K-Band Transmit Phased Array For Low Earth Orbit Satellite Communications

Thomas Watson, Stephen Miller, and Dennis Kershner

Raytheon Systems Company, Plano Texas

Godfrey Anzic

Glenn Research Center, Cleveland, Ohio 
Since its founding, NASA has been dedicated to the advancement of aeronautics and space science. The NASA Scientific and Technical Information (STI) Program Office plays a key part in helping NASA maintain this important role.

The NASA STI Program Office is operated by Langley Research Center, the Lead Center for NASA's scientific and technical information. The NASA STI Program Office provides access to the NASA STI Database, the largest collection of aeronautical and space science STI in the world. The Program Office is also NASA's institutional mechanism for disseminating the results of its research and development activities. These results are published by NASA in the NASA STI Report Series, which includes the following report types:

- TECHNICAL PUBLICATION. Reports of completed research or a major significant phase of research that present the results of NASA programs and include extensive data or theoretical analysis. Includes compilations of significant scientific and technical data and information deemed to be of continuing reference value. NASA's counterpart of peerreviewed formal professional papers but has less stringent limitations on manuscript length and extent of graphic presentations.

- TECHNICAL MEMORANDUM. Scientific and technical findings that are preliminary or of specialized interest, e.g., quick release reports, working papers, and bibliographies that contain minimal annotation. Does not contain extensive analysis.

- CONTRACTOR REPORT. Scientific and technical findings by NASA-sponsored contractors and grantees.
- CONFERENCE PUBLICATION. Collected papers from scientific and technical conferences, symposia, seminars, or other meetings sponsored or cosponsored by NASA.

- SPECIAL PUBLICATION. Scientific, technical, or historical information from NASA programs, projects, and missions, often concerned with subjects having substantial public interest.

- TECHNICAL TRANSLATION. Englishlanguage translations of foreign scientific and technical material pertinent to NASA's mission.

Specialized services that complement the STI Program Office's diverse offerings include creating custom thesauri, building customized data bases, organizing and publishing research results ... even providing videos.

For more information about the NASA STI Program Office, see the following:

- Access the NASA STI Program Home Page at http://www.sti.nasa.gov

- E-mail your question via the Internet to help@sti.nasa.gov

- Fax your question to the NASA Access Help Desk at (301) 621-0134

- Telephone the NASA Access Help Desk at (301) 621-0390

- Write to:

NASA Access Help Desk

NASA Center for AeroSpace Information 7121 Standard Drive

Hanover, MD 21076 
NASA/TM-2000-209779

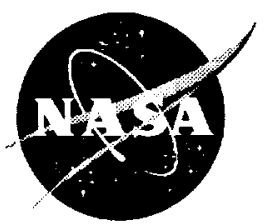

Design of a K-Band Transmit Phased Array For Low Earth Orbit Satellite Communications

Thomas Watson, Stephen Miller, and Dennis Kershner

Raytheon Systems Company, Plano Texas

Godfrey Anzic

Glenn Research Center, Cleveland, Ohio

Prepared for the

2000 IEEE International Conference on Phased Array Systems and Technology cosponsored by the AES, AP, and MTT

Dana Point, California, May 20-26, 2000

National Aeronautics and

Space Administration

Glenn Research Center 


\section{Acknowledgments}

The authors would like to acknowledge NASA Glenn Research Center, Raytheon RF/Microwave Department and Antenna/Nonmetallics Technology Center.

This report is a preprint of a paper intended for presentation at a conference. Because

of changes that may be made before formal publication, this preprint is made available with the understanding that it will not be cited or reproduced without the permission of the author.

Available from

NASA Center for Aerospace Information

7121 Standard Drive

Hanover, MD 21076

Price Code: A02
National Technical Information Service 5285 Port Royal Road Springfield, VA 22100

Price Code: A02 


\title{
DESIGN OF A K-BAND TRANSMIT PHASED ARRAY FOR LOW EARTH ORBIT SATELLITE COMMUNICATIONS
}

\author{
Thomas Watson, Stephen Miller, Dennis Kershner \\ Raytheon Systems Company \\ Plano, Texas 75086 \\ G. Art Anzic \\ National Aeronautics and Space Administration \\ Glenn Research Center \\ Cleveland, Ohio 44135
}

\begin{abstract}
$\underline{\text { Abstract }}$
The design of a light weight, low cost phased array antenna is presented. Multi-layer printed wiring board (PWB) technology is utilized for $\mathrm{RF}$ and $\mathrm{DC} /$ Logic manifold distribution. Transmit modules are soldered on one side and patch antenna elements are on the other, allowing the use of automated assembly processes. The $19 \mathrm{GHz}$ antenna has two independently steerable beams, each capable of transferring data at $622 \mathrm{Mbps}$. A passive, selfcontained phase change thermal management system is also presented.
\end{abstract}

\section{Experiment Description \& Objectives}

Rapid deployment of low and medium Earth orbit (LEO/MEO) satellite constellations, which will offer various narrow to wide band wireless communications services, will require phased array antennas which feature wide-angle and super agile electronic steering of one or more antenna beams. Phased array antennas are perfectly suited for this application. A MMIC- based, K-band phased array antenna is in development, under a cooperative agreement between NASA Glenn Research Center and Raytheon Systems Company. The transmit array, operating at $19 \mathrm{GHz}$, is a state-of-the-art design that features dual, independent, electronically steerable beam operation $\left( \pm 42^{\circ}\right)$, a stand-alone thermal management system and a high-density tile architecture. The tile integration technology ("flip chip MMIC tile") represents a major advancement in phased array engineering and holds much promise for reduced manufacturing costs.

The antenna system is scheduled to be completed in mid-2000. The array will be a critical component of the Direct Data Distribution $\left(D^{3}\right)$ flight experiment on a future Space Shuttle mission, as early as 2001 , with the objective of down linking wide band data rates to a small, tracking Earth terminal. Phased array antennas capable of providing a rapid direct downlink of large volumes of data from various space platforms are high on NASA's and the communications industry's priority lists.

Figure 1. Phased Array and Thermal System 


\section{Array Requirements}

Requirements for the $\mathrm{D}^{3}$ Array were determined from a combination of functional needs of NASA's $D^{3}$ flight experiment and performance requirements taken from the experiment link budget analysis. Functional requirements of the experiment include: frequency/bandwidth, number of beams, scan limits, polarization, DC power and weight/volume. Performance requirements derived from the link budget include: EIRP, cross-polarization, and intermodulation. A summary of the phased array performance goals is listed in Table 1.

\section{Table 1. Array Performance Goals}

\begin{tabular}{|l|l|}
\hline \multicolumn{1}{|c|}{ Parameter } & \multicolumn{1}{c|}{ Value } \\
\hline Frequency/Bandwidth & 18.8 to $19.3 \mathrm{GHz}$ \\
\hline Transmit Power & 20 Watts/beam \\
\hline EIRP at max. scan & $39.1 \mathrm{dBW}$ \\
\hline Number of Beams & 2 \\
\hline Maximum Scan Angle & $\pm 42^{\circ}$ in Az and EI \\
\hline Polarization & $\mathrm{RHCP} \& \mathrm{LHCP}$ \\
\hline Cross-polarization & $-15 \mathrm{~dB}$ \\
\hline Beamwidth & $6.4^{\circ} \times 6.4^{\circ}$ \\
\hline Sidelobe level & $-20 \mathrm{~dB}$, peak \\
\hline Intermodulation & $-25 \mathrm{dBc}$ \\
\hline DC power & $<390 \mathrm{Watts}$ \\
\hline Array Weight & $<3.8 \mathrm{~kg}$ \\
\hline Array Volume & $<5000 \mathrm{~cm}^{3}$ \\
\hline
\end{tabular}

Additional requirements due to the planned experiment on the Shuttle are environmental and safety related. The space environment requires special attention to thermal design of the active array. A separate thermal management system is required to handle the heat generated by the transmit modules. Special materials are used to accommodate the temperature and vacuum conditions. Space radiation is low at the Shuttle altitude, but radiation must be considered in selection of high speed digital circuits. Three levels of hardware and software interlocks are designed into the controller to eliminate the risk of $R F$ radiation to the astronauts.

\section{Array Description}

The array aperture is circular with edges formed due to the use of quad modules as tiles for array construction. Microstrip stacked patch radiating elements are arranged in an equilateral triangular grid with a separation of $9.75 \mathrm{~mm}$ to allow the antenna to scan to $42^{\circ}$ from boresight without grating lobes. To achieve the required 39.1 $\mathrm{dBW}$ effective isotropic radiated power (EIRP) at full scan, the array consists of 256 radiating elements. A $6 \mathrm{~dB}$ step taper has been implemented to control sidelobe levels. The 96 central and 160 outer elements are fed by 0.25 $\mu \mathrm{m}$ pHEMPT $150 \mathrm{~mW}$ and $37.5 \mathrm{~mW}$ MMIC amplifiers, respectively.

Each quad module contains 8, 4-bit phase shifters and 4 dual channel power amplifiers, allowing the array to form two independent, simultaneous beams. The output power is 20 Watts per beam. Array power dissipation is estimated at 346 Watts during the ON state with both beams active. The total dc power required by the array is estimated at 386 Watts.

The two beams are generated with opposite sense polarization, one right-hand circularly polarized, one as left-hand circularly polarized. This approach minimizes interference between beams and allows both beams to be simultaneously received by a single ground terminal. The current estimate is that the worst case polarization coupling level will be $-15 \mathrm{~dB}$. Predicted pattern performance is shown at the end of this paper.

As shown in Figure 1, the antenna is fabricated using a tile method of construction producing a high-density, low-profile assembly. The main internal assembly, the RF/DC manifold, is a multi-layer printed wiring board consisting of 27 metal layers separated by dielectric material of various thicknesses. These layers include the etched circuits for the two corporate feed RF divider networks for the two beams, the dc power distribution circuits, the logic and control networks, and the microstrip patch elements with their associated $90^{\circ}$ branch-line hybrids to form circularly polarized waves. The layer count also includes all of the ground and joining layers required between sub-panels of the multilayer board assembly. The quad modules are attached directly to the RF/DC manifold with a solder ball reflow process. 
A beam steering computer (BSC) has been developed by Raytheon to control all operations of the antenna. The BSC consists of a commercially available VME processor card and a custom mezzanine card to control array functions in response to commands received from the payload control computer via the VME bus.

\section{Tile Description}

The $D^{3}$ Array is populated with 64 tile modules mounted to the RF DC manifold in a rectangular grid. Tile size is $16.4 \mathrm{~mm} \mathrm{~W} \times 19.0 \mathrm{~mm} \mathrm{~L} \times 2.67$ $\mathrm{mm} \mathrm{H}$ weighing approximately 3.5 grams. Each tile consists of a quad module as shown in Figure 2. The tile modules each contain 8 independently controlled RF paths partitioned in quadrants since each tile must feed the two independent beams to four radiating elements. The array $6 \mathrm{~dB}$ step taper is implemented with 24 high power modules in the center of the array and 40 low power modules around the periphery.

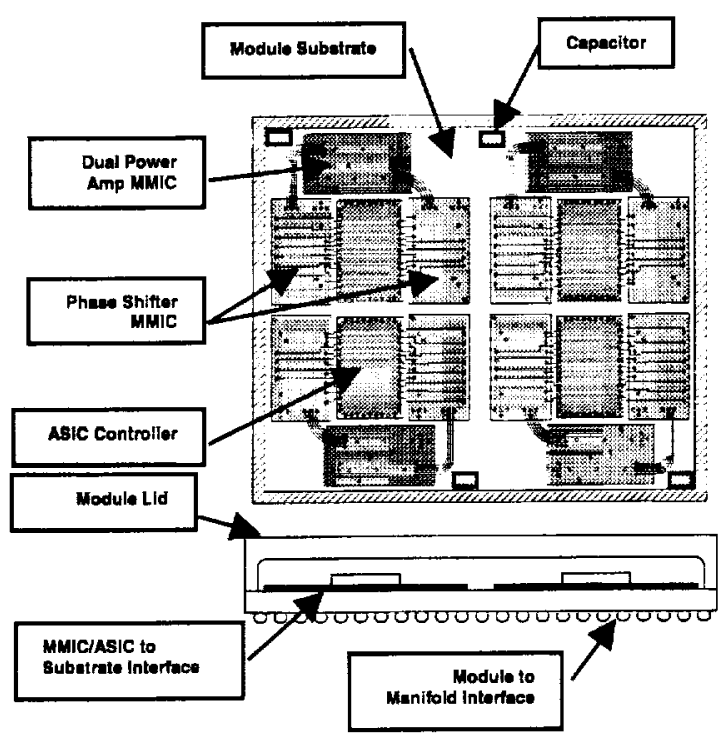

Figure 2. Module Layout

The $\mathrm{D}^{3}$ tile module design evolved from $\mathrm{RF}$ and thermal performance, available area, fabrication/production issues and cost goals. The major module components are shown in Figure 2. The module mounts to the RF/DC manifold using a Ball Grid Array (BGA) using $0.508 \mathrm{~mm}$ diameter $90 \mathrm{Sn} / 10 \mathrm{~Pb}$ alloy solder balls. The module substrate is $0.381 \mathrm{~mm}$ thick Alumina with appropriate metallization for signal routing, thermal conduction and BGA attachment with $0.127 \mathrm{~mm}$ diameter filled through vias for RF/DC/logic I/O and thermal conduction. Each quadrant contains a silicon ASIC controller, a GaAs dual channel power amplifier MMIC, and two GaAs phase shifter/attenuator MMICs. The ICs are flip chip mounted to the substrate using $0.127 \mathrm{~mm}$ diameter $63 \mathrm{SN} / 37 \mathrm{~Pb}$ alloy solder balls. There are 4 surface mount chip capacitors for local energy storage and RF bypass. The MMICs and capacitors account for $60 \%$ of the substrate area demonstrating the increased packing density afforded by flip chip IC mounting. A copper alloy lid attached to the substrate completes the module package and serves as the main thermal interface.

\section{Monolithic Microwave Integrated Circuit (MMIC)}

The $\mathrm{D}^{3}$ Array modules contain Embedded Transmission Line (ETL) MMICs on a GaAs substrate as shown in Figure 3 [1]. ETL MMICs utilize matching circuits, transmission lines, and lumped, passive components in a low loss dielectric with a topside ground plane. The ground plane reduces unwanted interactions between the MMIC and its surrounding environment producing more consistent RF performance during production process development.

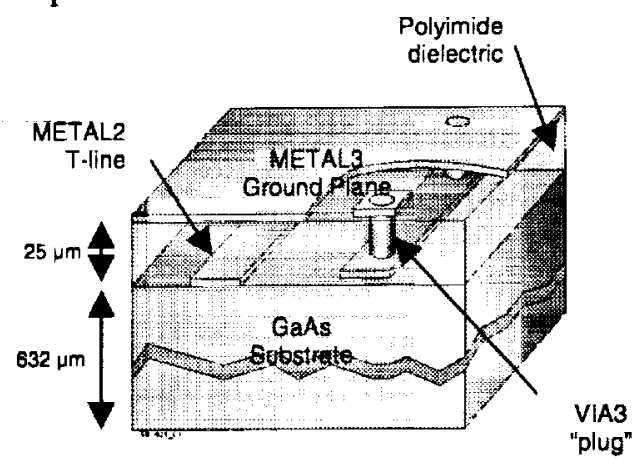

Figure 3. ETL MMIC

There are three MMIC designs: the phase shifter/attenuator, high power dual channel power amplifier and low power dual channel power amplifier. The phase shifter/attenuator 
MMIC size is $4.47 \times 2.47 \mathrm{~mm}$. The RF signal enters the MMIC and travels through an amplifier followed by 4 attenuator bits, another amplifier stage, 4 phase shifter delay line and then exits the MMIC. The amplifier stages offset transmission line losses within the MMIC for a nominal net gain of $0 \mathrm{~dB}$.

The dual channel high power amplifier MMIC size is $4.47 \times 2.47 \mathrm{~mm}$. Two RF signals enter the MMIC and each signal path travels through three amplifier stages before exiting the MMIC. Net gain is $+21 \mathrm{~dB}$ with $+22 \mathrm{dBm}$ RF output power at $1 \mathrm{~dB}$ compression. The dual channel low power amplifier MMIC is similar to its high power counterpart except there are only two amplifier stages producing $+15 \mathrm{~dB}$ gain with $+16 \mathrm{dBm}$ RF output power at $1 \mathrm{~dB}$ compression.

\section{Thermal Management System}

A phase change thermal management system has been developed to provide a platform independent heat management system. The system also provides the structural interface between the array and the Shuttle Hitchhiker canister. It is sized to maintain transistor junction temperatures below $100^{\circ} \mathrm{C}$ and to maintain an array thermal gradient below $10^{\circ} \mathrm{C}$. The phase change system is a $20 \mathrm{~cm}$ diameter brazed housing with porous aluminum "foam" inside, as shown in Figure 1. The "foam" is filled with paraffin wax phase change material. As the antenna modules heat up, the solid wax absorbs the heat energy and changes to the liquid phase. During the phase change period, the wax temperature is maintained at approximately the melt point. This provides a constant-temperature interface for the array electronic modules. During periods in which the antenna modules are off, the wax releases its stored heat and changes back to the solid phase, thereby tempering extreme temperature excursions. Heat pipes are arranged radially to maintain the array temperature gradients at an acceptable level. This is made necessary due to the higher power center modules described above.

\section{Conclusions}

High performance, lightweight, low cost antennas are needed for future satellite communication systems. A recent advance has been the development of a two beam, K-band, transmit array to demonstrate high data rate link from the Shuttle to a NASA ground station. Many advanced technologies have been designed into this antenna in order to meet the requirements of the experiment. A successful demonstration will validate these technologies for future satellite applications.

\section{$\underline{\text { References }}$}

[1] H. Tserng, et. al., "Embedded Transmission-Line (ETL) MMIC for Low-Cost High-Density Wireless Communication Applications," IEEE Transactions on Microwave Theory and Techniques, vol. 45 No. 12, December, 1997.

\section{Array Patterns on Boresight}
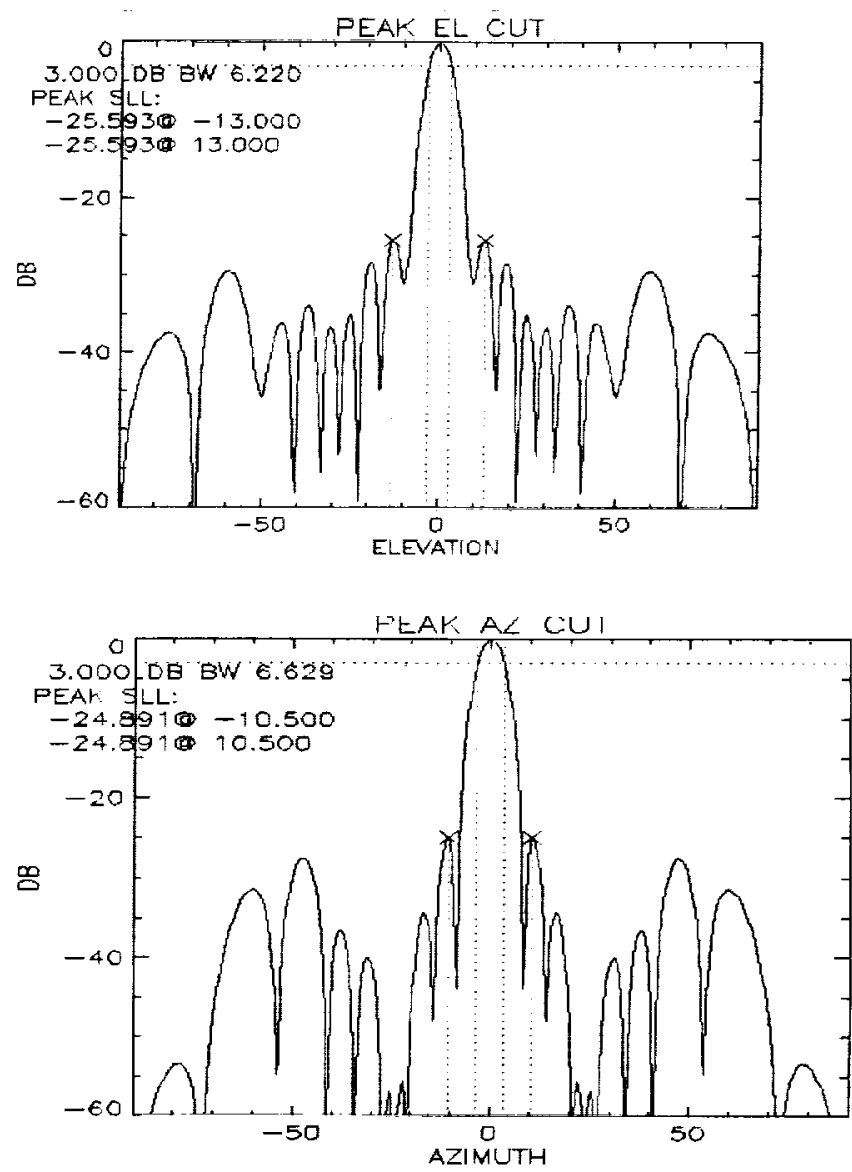

$=$

$-$

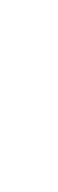
7 


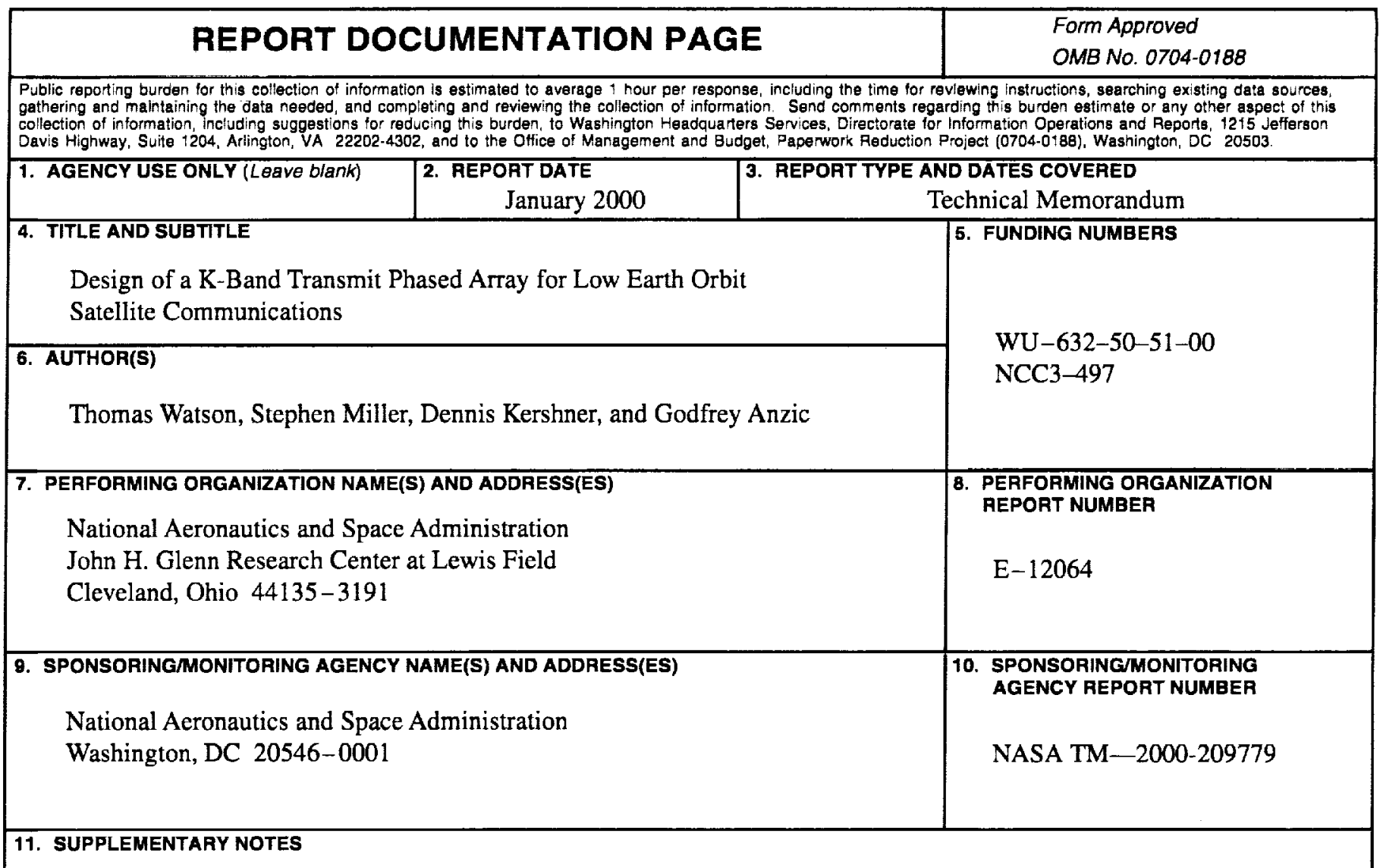

Prepared for the 2000 IEEE International Conference on Phased Array Systems and Technology cosponsored by the AES, AP, and MTT, Dana Point, California, May 20-26, 2000. Thomas Watson, Stephen Miller, and Dennis Kershner, Raytheon Systems Company, P.O. Box 869305, Plano, Texas 75086; Godfrey Anzic, NASA Glenn Research Center. Responsible person, Godfrey Anzic, organization code 5640, (216) 433-3570.

12a. DISTRIBUTIONAVAILABILITY STATEMENT

12b. DISTRIBUTION CODE

Unclassified - Unlimited

Subject Category: 32

Distribution: Nonstandard

This publication is available from the NASA Center for AeroSpace Information, (301) 621-0390.

13. ABSTRACT (Maximum 200 words)

The design of a light weight, low cost phased array antenna is presented. Multilayer printed wiring board (PWB) technology is utilized for RF and DC/Logic manifold distribution. Transmit modules are soldered on one side and patch antenna elements are on the other, allowing the use of automated assembly processes. The $19 \mathrm{GHz}$ antenna has two independently steerable beams, each capable of transferring data at $622 \mathrm{Mbps}$. A passive, self-contained phase change thermal management system is also presented.

\begin{tabular}{|c|c|c|c|}
\hline \multicolumn{3}{|l|}{ 14. SUBJECT TERMS } & $\begin{array}{c}\text { 15. NUMBER OF PAGES } \\
10\end{array}$ \\
\hline \multicolumn{3}{|c|}{ MMIC; Amplifiers; K-band; Satellite communications; Phased array; pHEMT; ETL } & 16. PRICE CODE \\
\hline & & & $\mathrm{AUL}$ \\
\hline $\begin{array}{l}\text { 17. SECURTY CLASSIFICAIION } \\
\text { OF REPORT }\end{array}$ & $\begin{array}{l}\text { 18. SECUAITY CLASSIFICATION } \\
\text { OF THIS PAGE }\end{array}$ & $\begin{array}{l}\text { 19. SEECHITY CLASSIFICATION } \\
\text { OF ABSTRACT }\end{array}$ & 20. LIMITATION OF ABSTRACT \\
\hline Unclassified & Unclassified & Unclassified & \\
\hline
\end{tabular}

